\title{
Neutrophil-to-Lymphocyte Ratio and Mean Platelet Volume in Chronic Otitis Media with or Without Cholesteatoma
}

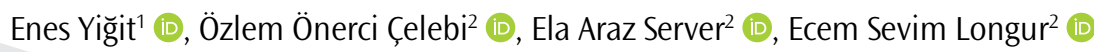

Introduction: The neutrophil-to-lymphocyte ratio (NLR) can be used as a systemic inflammatory marker and the increased mean platelet volume (MPV) indicates that the inflammation is more intense. The aim of the study is to show the NLR and MPV values in chronic otitis media with or without ossicular/bony destruction or cholesteatoma and to investigate the predictive values of these parameters..

Methods: Patients with chronic otitis media were retrospectively analyzed and divided into three groups: group 1 had only tympanic membrane perforation without any ossicular/bony erosion or cholesteatoma, group 2 had ossicular/bony erosion but no cholesteatoma, and group 3 had cholesteatoma. The control group (group 0) included subjects who were scheduled for septoplasty in our hospital, who did not have any otologic complaints, and who had normal otologic examination. Blood samples including complete blood count were obtained from all patients in their preoperative visit. The neutrophil, lymphocyte, platelet, and MPV values were obtained. NLR was calculated by dividing the number of neutrophils by the number of lymphocytes.

Results: The study included 157 patients and 50 controls. There were 50 patients in groups 1 and 2 and 57 patients in group 3. The neutrophil, lymphocyte, NLR, MPV, and red blood cell distribution width values showed no statistically significant difference between the groups.

Conclusion: Although NLR is related to the prognosis and severity of several diseases, we found no association between NLR, MPV and chronic ear disease. NLR and MPV also have no value in predicting prognosis and the accompanying ossicular or bony erosion accompanying COM

Keywords: Neutrophil-to-lymphocyte, mean platelet volume, chronic otitis

ORCID IDs of all authors: SE.Y. 0000-0002-98536238; 0̈.0̈.C.. 0000-0001-8170-7443; E.A.S. 00000002-8462-3605; E.S.L. 0000-0001-6256-2015.

'Department of Otorhinolaryngology/Head and Neck Surgery, Lüleburgaz State Hospital, Kırklareli, Turkey

${ }^{2}$ Department of Otorhinolaryngology/Head and Neck Surgery, İstanbul Training and Research Hospital, İstanbul, Turkey

\section{Address for Correspondence:}

Ela Araz Server

E-mail: serverela@hotmail.com

Received: 03.03.2018

Accepted: 18.04.2018

(C) Copyright 2018 by Available online at istanbulmedicaljournal.org

\section{Introduction}

Chronic otitis media (COM) leads to a chronic inflammation of the middle ear mucosa which can be accompanied by ossicular erosions and/or bony destructions. When there is also an accumulation of keratinizing squamous epithelium in these spaces, it is called COM with cholesteatoma. Oxidative stress and inflammation have been shown to play important roles in several middle ear infections (1-4).

Lymphopenia and neutrophilia show the general inflammatory status of the body (5-7). The neutrophil-to-lymphocyte ratio (NLR) can be used as a systemic inflammatory marker, as it reflects both the increase in neutrophils and the decrease in lymphocytes $(5,8)$. Mean platelet volume (MPV) can also be used as a marker of inflammation $(9,10)$. It measures the volume of circulating thrombocytes, and an increased MPV indicates that the inflammation is more intense $(9,10)$.

The NLR and MPV values have been previously studied in COM, but, to our knowledge, the difference in inflammatory values between patients with different presentations of COM has not been previously investigated. The aim of the present study was to show the NLR and MPV values in patients who have COM with or without ossicular/bony destruction or cholesteatoma, to compare the results in different groups, and to investigate the predictive values of these parameters in COM.

\section{Methods}

This was a retrospective study. Istanbul Training and Research Hospital Ethics Committee (29.12.2017-1158) approved the study in accordance with the Declaration of Helsinki. Patients with COM who had surgery in our hospital were included in the study. Operative notes, detailed patient data including history, and preoperative blood tests were recorded from retrospective review of patient records. Revision cases and cases without detailed operative note or preoperative blood count were excluded from the study. Patients who had complications secondary to COM were also excluded. 
Table 1. Neutrophil-to-lymphocyte ratio values in patients with chronic otitis media (groups 1, 2, and 3) and control group (group 0)

\begin{tabular}{|c|c|c|c|c|c|c|c|c|c|c|}
\hline & & Group 0 & & Group 1 & & Group 2 & & Group 3 & & p \\
\hline \multirow[t]{2}{*}{ Age } & Mean $\pm S D$ & $31.9 \pm 10.6$ & & $32.6 \pm 12.3$ & & $37.8 \pm 14.4$ & & $35.8 \pm 12.0$ & & \multirow{2}{*}{$0.067^{\mathrm{K}}$} \\
\hline & Median & 28.0 & & 31.0 & & 37.0 & & 34.0 & & \\
\hline \multirow[t]{2}{*}{ Gender } & Female $\quad \mathrm{n}-\%$ & 20 & $40.0 \%$ & 26 & $52.0 \%$ & 26 & $52.0 \%$ & 18 & $31.6 \%$ & \multirow{2}{*}{$0.090^{2} \chi^{2}$} \\
\hline & Male $\quad \mathrm{n}-\%$ & 30 & $60.0 \%$ & 24 & $48.0 \%$ & 24 & $48.0 \%$ & 39 & $68.4 \%$ & \\
\hline \multirow[t]{2}{*}{ Neutrophil } & Mean $\pm S D$ & $40 \pm 1.1$ & & $4.2 \pm 1.5$ & & $4.2 \pm 1.1$ & & $4.3 \pm 1.2$ & & \multirow{2}{*}{$0.639^{A}$} \\
\hline & Median & 3.8 & & 4.2 & & 4.1 & & 4.3 & & \\
\hline \multirow[t]{2}{*}{ Lymphocyte } & Mean $\pm S D$ & $2.3 \pm 0.5$ & & $2.3 \pm 0.6$ & & $2.4 \pm 0.5$ & & $2.4 \pm 0.6$ & & \multirow{2}{*}{$0.803^{\mathrm{A}}$} \\
\hline & Median & 2.4 & & 2.2 & & 2.3 & & 2.3 & & \\
\hline \multirow[t]{2}{*}{ NLR } & Mean $\pm S D$ & $1.8 \pm 0.7$ & & $1.9 \pm 0.8$ & & $1.9 \pm 0.7$ & & $1.9 \pm 0.5$ & & \multirow{2}{*}{$0.878^{\mathrm{K}}$} \\
\hline & Median & 1.7 & & 1.7 & & 1.7 & & 1.8 & & \\
\hline \multirow[t]{2}{*}{ MPV } & Mean $\pm S D$ & $88.3 \pm 4.2$ & & $87.3 \pm 4.7$ & & $87.5 \pm 3.9$ & & $87.1 \pm 3.5$ & & \multirow{2}{*}{$0.603^{\mathrm{K}}$} \\
\hline & Median & 87.4 & & 86.9 & & 87.3 & & 86.8 & & \\
\hline \multirow[t]{2}{*}{ RDW3 } & Mean $\pm S D$ & $13.1 \pm 0.7$ & & $13.4 \pm 1.1$ & & $13.3 \pm 0.7$ & & $13.3 \pm 0.6$ & & \multirow{2}{*}{$0.559^{k}$} \\
\hline & Median & 13.1 & & 13.2 & & 13.2 & & 13.1 & & \\
\hline
\end{tabular}

${ }^{A}$ ANOVA, ${ }^{K}$ Kruskal-Wallis, $\chi^{2}$ Chi-square test, NLR: neutrophil-to-lymphocyte ratio; MPV: mean plasma volume; RDW: red blood cell distribution width; SD: standard deviation

Patients with COM were divided into three groups: group 1 had only tympanic membrane perforation without any ossicular/ bony erosion or cholesteatoma, group 2 had COM and ossicular/ bony erosion but without cholesteatoma, and group 3 included patients with COM with cholesteatoma. Patients with only tympanic membrane perforation (corresponding to group 1) who had granulation tissue or tympanosclerosis in the middle ear were excluded.

The control group (group 0) included subjects who were scheduled for septoplasty in our hospital, who did not have any otologic complaints, and who had normal otologic examination. All these preoperative patients scheduled for septoplasty had normal preoperative test values and normal otologic exam under pneumatic otoscopy. Patients who had active ear disease or any infectious, inflammatory, or systemic disease that could have an impact on blood counts were excluded. Patients who were noted to have obstructive sleep apnea syndrome (OSAS) or had symptoms of OSAS and with severe septal deviation totally obstructing the airway, bilateral septal deviation, and adenoid and tonsillar hypertrophy obstructing the airway were also excluded.

Blood samples including complete blood count were obtained from all patients in their preoperative visit. The neutrophil, lymphocyte, platelet, MPV, and red blood cell distribution width (RDW) values were obtained. NLR was calculated by dividing the number of neutrophils by the number of lymphocytes.

\section{Statistical Analysis}

Statistical analyses were performed using Statistical Package for the Social Sciences for Windows version 22.0 (IBM SPSS Corp.; Armonk, NY, USA). Descriptive statistics including mean, standard deviation, median, and minimum-maximum values of the variables of the study population were analyzed. The KolmogorovSmirnov test was used for testing the normality of data. The Kruskal-Wallis test was used for comparison of non-normally distributed data (NLR, MPV, and RDW) between the control group and the four different subgroups of cases. The Mann-Whitney $U$ test was also used for comparison of non-normally distributed data between the control group and the COM case group (sum of groups 1, 2, and 3). The ANOVA test was used for comparison of normally distributed data (neutrophil and lymphocyte) between the control group and the four different subgroups. The independent samples t-test was also used for comparison of normally distributed data between the control group and the COM case group (sum of groups 1, 2, and 3). A p value $<0.05$ was considered as statistically significant.

\section{Results}

The study included 157 patients. There were 70 (44.6\%) female and 87 (55.4\%) male patients. The control group comprised 50 subjects, with $20(40 \%)$ female and $30(60 \%)$ male patients. There were 50 patients in groups 1 and 2 and 57 patients in group 3. The total mean age of the patient groups (groups $1+2+3$ ) was $35.3 \pm 12.3$ years. The mean age of the control group (group 0) was $31.9 \pm 10.6$ years. There was no statistically significant difference between age and gender distribution of the four different groups $(p>0.05)$. The neutrophil, lymphocyte, NLR, MPV, and RDW values showed no statistically significant difference between the groups $(p>0.05)$. Table 1 shows the values for each group.

Then, all patients with COM (groups 1, 2, and 3) were combined and compared with the control group (group 0). There was no statistically significant difference between age and gender distribution of the patients with COM and the control group ( $p>0.05)$. The neutrophil, lymphocyte, NLR, MPV, and RDW values showed no statistically significant difference between these groups $(p>0.05)$.

\section{Discussion}

Chronic otitis media is the inflammation of the middle ear mucosa and the temporal bone for $>3$ months, accompanied by 
the perforation of the tympanic membrane. Chronic inflammation may act differently in different patients. In some patients, there is only a perforation of the tympanic membrane without any ossicular or bony destruction. However, in some patients, in addition to tympanic membrane perforation, there is also an erosion or even destruction of the ossicles. This may or may not be accompanied by growth of the keratinized epithelium in the middle ear, cholesteatoma, which is a lytic process and is generally accompanied by bony and ossicular erosions. These different inflammatory processes of the middle ear act differently, and the surgery to be performed to each of these pathologies is different. It is not easy to foresee which patients with COM will develop ossicular/bony erosion or cholesteatoma. It is also hard to predict what to expect during surgery, as the surgical approaches to all these pathologies differ. Thus, predictors that would differentiate these different types of chronic ear disease prior to surgery are necessary. This would help a physician to inform his patient about the progress and prognosis of his chronic ear disease and about what to expect after surgery. It would also be beneficial for a physician to predict the status of the middle ear prior to surgery. Thus, we aimed to compare the inflammatory values in these different types of COM. Although one would expect that all these processes causing inflammation would affect the NLR and MPV values, the present study showed that COM with or without ossicular/bony erosion or cholesteatoma had no impact on these values. Even the bone erosion and the osteoclastic activity seen in cholesteatoma had no effect on these values. These findings show that the inflammation in these pathologies remains local and does not lead to a systemic inflammatory reaction. Inflammations of the middle ear cavity with or without an accompanying ossicular/bony erosion or cholesteatoma do not increase the NLR or MPV values.

Neutrophil-to-lymphocyte ratio and MPV have been recognized as a systemic inflammatory marker and predictor of poor clinical outcomes for many diseases (11-16). Many biomarkers are available to detect inflammatory cytokines; however, determination of NLR and MPV is simple and readily available ways to detect inflammation without an extra cost. A complete blood cell count is sufficient to determine both values.

Neutrophil-to-lymphocyte ratio has been studied in various diseases, such as cardiovascular diseases, chronic renal disease and diabetic nephropathy, and several types of cancer $(11-15,17)$, and in various otorhinolaryngological disorders including malignities (18-25), OSAS, Bell's palsy, sudden hearing loss, tinnitus, adenoidectomy, and tonsillectomy $(7,26-30)$. It has also been studied in patients with otitis media to detect the effects of inflammation in the middle ear on the inflammatory blood parameters. The effects of oxidative stress on acute otitis media, otitis media with effusion (OME), COM, and tympanosclerosis have been shown, suggesting the role of inflammation in various inflammatory otologic disorders (1-4, 30-33). The studies showed that NLR is higher in patients with OME and could help in determining the viscosity of the fluid accumulated in the middle ear (30-33). OME can act as a precursor for COM, and the inflammation observed in these studies may act by triggering the inflammatory pathway leading to COM with or without cholesteatoma. Tansuker et al. investigated the predictive value of NLR to differentiate active from inactive COM and concluded that NLR did not help to differentiate active from inactive COM (16).
The NLR value has also been studied in patients with cholesteatoma. Inflammation causes squamous epithelial transformation in the middle ear leading to cholesteatoma, which may cause lytic and destructive inflammatory reaction. Kilickaya et al. (34) investigated the systemic inflammatory effect of COM with cholesteatoma and showed that NLR has no predictive value with respect to bone erosions and associated complications in patients with cholesteatoma. Other than that, Eryilmaz et al. (10) studied the NLR values in pediatric patients compared with those in COM with and without cholesteatoma. NLR in the two groups showed no statistically significant difference. However, MPV was lower in patients with cholesteatoma than in the controls, which they suggested could act as a predictor for cholesteatoma.

Mean platelet volume has also been shown to be a marker of inflammation and has been studied in various otolaryngological diseases $(35,36)$. In addition, it has been studied in chronic ear disease. It was reported that MPV is lower in pediatric patients with cholesteatoma, and that it has a role in predicting cholesteatoma in children (10). However, this decrease in MPV has not been shown in our study.

As complications of COM may lead to leukocytosis and systemic toxicity, patients who had complications secondary to COM were excluded in the present study. This is important as these inflammatory results could affect our results. Other than that, as hypoxia can cause inflammatory and oxidative response $(7,36,37)$, patients who were prone to hypoxic conditions, who had OSAS or had symptoms of OSAS, and with severe septal deviation totally obstructing the airway, bilateral septal deviations, and adenoid and tonsillar hypertrophy were excluded to eliminate the impact of hypoxia on blood test results. One limitation of the present study is its retrospective design and lack of follow-up data after surgery.

To the best of our knowledge, this is the first study to investigate NLR and MPV in patients with COM with or without ossicular/bony destruction or cholesteatoma. Our study shows that a chronic inflammation in the middle ear cavity with or without ossicular/ bony erosion or cholesteatoma remains local and does not trigger a systemic inflammatory reaction.

\section{Conclusion}

To our knowledge, the present study is the first to assess the MPV and NLR values in patients with COM and to investigate whether these values have any value in predicting the ossicular and bony erosions and presence of cholesteatoma in advance. However, this effect has not been shown in our study. Although NLR is related to the prognosis and severity of several diseases, we found no association between NLR, MPV, and chronic ear disease. NLR and MPV also have no value in predicting the prognosis and the ossicular or bony erosion accompanying COM.

Ethics Committee Approval: Ethics committee approval was received for this study from the ethics committee of istanbul Training and Research Hospital (29.12.2017-1158).

Informed Consent: Due to the retrospective design of the study, informed consent was not taken. 
Peer-review: Externally peer-reviewed

Author Contributions: Concept - E.Y., Ö.Ö.Ç., E.A.S., E.S.L.; Design - E.Y., Ö.Ö.C., E.A.S., E.S.L.; Supervision - E.Y., Ö.Ö.C.., E.A.S., E.S.L.; Resources - E.Y., Ö.Ö.C., E.A.S., E.S.L.; Materials - E.Y., Ö.Ö.Ç., E.A.S., E.S.L.; Data Collection and/or Processing - E.Y., Ö.Ö.Ç., E.A.S., E.S.L.; Analysis and/or Interpretation - E.Y., Ö.Ö.Ç., E.A.S., E.S.L.; Literature Search - E.Y., Ö.Ö.C.., E.A.S., E.S.L.; Writing Manuscript - E.Y., Ö.Ö.Ç., E.A.S., E.S.L.; Critical Review - E.Y., Ö.Ö.Ç., E.A.S., E.S.L.; Other - E.Y., Ö.Ö.Ç., E.A.S., E.S.L.

Conflict of Interest: The authors have no conflict of interest to declare.

Financial Disclosure: The authors declared that this study has received no financial support.

\section{References}

1. Yilmaz T, Kocan EG, Besler HT, Yilmaz G, Gursel B. The role of oxidants and antioxidants in otitis media with effusion in children. Otolaryngol Head Neck Surg 2004; 131: 797-803. [CrossRef]

2. Karlidag T, Ilhan N, Kaygusuz I, Keles E, Yalcin S. Comparison of free radicals and antioxidant enzymes in chronic otitis media with and without tympanosclerosis. Laryngoscope 2004; 114: 85-9. [CrossRef]

3. Baysal E, Aksoy N, Kara F, Taysi S, Tașkın A, Bilinç H, et al. Oxidative stress in chronic otitis media. Eur Arch Otorhinolaryngol 2013; 270: 1203-8. [CrossRef]

4. Garça MF, Aslan M, Tuna B, Kozan A, Cankaya H. Serum Myeloperoxidase Activity, Total Antioxidant Capacity and Nitric Oxide Levels in Patients with Chronic Otitis Media. J Membrane Biol 2013; 246: 519-24. [CrossRef]

5. Yenigun A. The efficacy of tonsillectomy in chronic tonsillitis patients as demonstrated by the neutrophil-to-lymphocyte ratio. J Laryngol Otol 2015; 129: 386-91. [CrossRef]

6. Zahorec R. Ratio of neutrophil to lymphocyte counts-rapid and simple parameter of systemic inflammation and stress in critically ill. Bratisl Lek Listy 2001; 102: 5-14.

7. Derin S, Erdogan S, Sahan M, Topal H, Sozen H. Neutrophil-Lymphocyte Ratio in Patients with Adenoidectomy. J Clin Diagn Res 2016; 10: MC03-5.

8. Roxburgh CS, McMillan DC. Role of systemic inflammatory response in predicting survival in patients with primary operable cancer. Future Oncol 2010; 6: 149-63. [CrossRef]

9. Gasparyan AY, Ayvazyan L, Mikhailidis DP, Kitas GD. Mean Platelet Volume: A Link Between Thrombosis and Inflammation? Curr Pharm Des 2011; 17: 47-58.

10. Eryilmaz, MA, Derin S. Mean Platelet Volume as a Potential Predictor of Cholesteatoma in Children. J Craniofac Surg 2016; 27: e575-8

11. Tamhane UU, Aneja S, Montgomery D, et al. Association between admission neutrophil to lymphocyte ratio and outcomes in patients with acute coronary syndrome. Am J Cardiol 2008;102:653-7 [CrossRef]

12. Halazun KJ, Aldoori A, Malik HZ, Rogers EK, Eagle KA, Gurm HS. Elevated preoperative neutrophil to lymphocyte ratio predicts survival following hepatic resection for colorectal liver metastases. Eur J Surg Oncol 2008; 34: 55-60. [CrossRef]

13. Arruda-Olson AM, Reeder GS, Bell MR, et al. Neutrophilia predicts death and heart failure after myocardial infarction: a community-based study. Circ Cardiovasc Qual Outcomes 2009;2:656-62. [CrossRef]

14. Gibson PH, Croal BL, Cuthbertson BH, Weston SA, Roger VL. Preoperative neutrophil lymphocyte ratio and outcome from coronary artery bypass grafting. Am Heart J 2007; 154: 995-1002. [CrossRef]

15. Cedrés S, Torrejon D, Martínez A, Martinez P, Navarro A, Zamora E, et al. Neutrophil to lymphocyte ratio (NLR) as an indicator of poor prognosis in stage IV non-small cell lung cancer. Clin Transl Oncol 2012; 14: 864-9. [CrossRef]

16. Tansuker HD, Eroğlu S, Yenigun A, Taskin U, Oktay MF. Can Serum Neutrophil-to-Lymphocyte Ratio Be a Predictive Biomarker to Help Differentiate Active Chronic Otitis Media From Inactive Chronic Otitis Media? J Craniofac Surg 2017; 28: e260-3.

17. Huang W, Huang J, Liu Q, Lin F, He Z, Zeng Z, et al. Neutrophil-lymphocyteratio is a reliablepredictive marker forearly-stage diabetic nephropathy. Clin Endocrinol (Oxf) 2015; 82: 229-33. [CrossRef]
18. Kara M, Uysal S, Altinisik U, Cevizci S, Güçlü O, Derekoy FS. The pre-treatment neutrophil-to-lymphocyte ratio, platelet-to-lymphocyte ratio, and red cell distribution width predict prognosis in patients with laryngeal carcinoma. Eur Arch Otorhinolaryngol 2017; 274: 53542. [CrossRef]

19. Perisanidis C, Kornek G, Poschl PW, Holzinger D, Pirklbauer K, Schopper $C$, et al. High neutrophil to-lymphocyte ratio is an independent marker of poor disease specific survival in patients with oral cancer. Med Oncol 2013; 30: 334-5. [CrossRef]

20. Ozturk K, Akyildiz NS, Uslu M, Gode S, Uluoz U. The effect of preoperative neutrophil, platelet and lymphocyte counts on local recurrence and survival in early-stage tongue cancer. Eur Arch Otorhinolaryngol 2016; 273: 4425-9. [CrossRef]

21. Kum RO, Ozcan M, Baklacı D. Elevated neutrophil-to lymphocyte ratio in squamous cell carcinoma of larynx compared to benign and precancerous laryngeal lesions. Asian Pac J Cancer Prev 2014; 15: 7351-5. [CrossRef]

22. Zeng YC, Chi F, Xing R, Xue M, Wu LN, Tang MY, et al. Pre-treatment neutrophil-to-lymphocyte ratio predicts prognosis in patients with locoregionally advanced laryngeal carcinoma treated with chemoradiotherapy. Jpn J Clin Oncol 2016; 46: 126-31.

23. Salim DK, Mutlu H, Eryilmaz MK, Salim O, Musri FY, Tural D, et al. Neutrophil to lymphocyte ratio is an independent prognostic factor in patient with recurrent or metastatic head and neck squamous cell cancer. Mol Clin Oncol 2015; 3: 839-42. [CrossRef]

24. Haddad CR, Guo L, Clarke S, Guminski A, Back M, Eade T. Neutrophil-to-lymphocyte ratio in head and neck cancer. J Med Imaging Radiat Oncol 2015; 59: 514-9. [CrossRef]

25. Rachidi S, Wallace K, Wrangle JM, Day TA, Alberg AJ, Li Z. Neutrophil-to lymphocyte ratio and overall survival in all sites of head and neck squamous cell carcinoma. Head Neck 2015; 38: E1068-74.

26. Ozbay I, Kahraman C, Balikci HH, Kucur C, Kahraman NK, Ozkaya DP, et al. Neutrophil-to-lymphocyte ratio in patients with severe tinnitus: prospective, controlled clinical study. J Laryngol Otol 2015; 129: 544-7. [CrossRef]

27. Chung JH, Lim J, Jeong JH, Kim KR, Park CW, Lee SH. The significance of neutrophil to lymphocyte ratio and platelet to lymphocyte ratio in vestibular neuritis. Laryngoscope 2015; 125: E257-61.

28. Bucak A, Ulu S, Oruc S, Yucedag F, Tekin MS, Karakaya F, et al. Neutrophil-to-lymphocyte ratio as a novel-potential marker for predicting prognosis of Bell palsy. Laryngoscope 2014; 124: 1678-81. [CrossRef]

29. Karli R, Alacam H, Unal R, Kucuk H, Aksoy A, Ayhan E. Mean platelet volume: is it a predictive parameter in the diagnosis of sudden sensorineural hearing loss? Indian J Otolaryngol Head Neck Surg 2013; 65: 350-3.

30. Elbistanli MS, Kocak HE, Acipayam H, Yigider AP, Keskin M, Kayhan FT. The Predictive Value of Neutrophil-Lymphocyte and Platelet-Lymphocyte Ratio for the EffusionViscosity in Otitis Media With Chronic Effusion. J Craniofac Surg 2017; 28: e244-7.

31. Yellon RF, Leonard G, Marucha PT, Craven R, Carpenter RJ, Lehmann WB, et al. Characterization of cytokines present in middle ear effusions. Laryngoscope 1991; 101: 165-9. [CrossRef]

32. Smirnova MG, Kiselev SL, Gnuchev NV, Birchall JP, Pearson JP. Role of the proinflammatory cytokines tumor necrosis factor-alpha, interleukin-1 beta, interleukin- 6 and interleukin-8 in the pathogenesis of the otitis media with effusion. Eur Cytokine Netw 2002; 13: 161-72.

33. Atan D, Apaydin E, Ozcan KM, Dere H. New diagnostic indicators in chronic otitis media with effusion: neutrophil to lymphocyte ratio and thrombocyte lymphocyte ratio. ENT Updates 2016; 6: 12-5. [CrossRef]

34. Kılıckaya MM, Aynali G, Tuz M, Bagcı O. Is There A Systemic Inflammatory Effect of Cholesteatoma? Int Arch Otorhinolaryngol 2017; 21: 42-5.

35. Unlu I, Kesici GG, Onec B, Yaman H, Guclu E. The effect of duration of nasal obstruction on mean platelet volume in patients with marked nasal septal deviation. Eur Arch Otorhinolaryngol 2016; 273: 401-5. [CrossRef] 
36. Rahangdale S, Yeh SY, Novack V, Stevenson K, Barnard MR, Furman MI, et al. The influence of intermittent hypoxemia on platelet activation in obese patients with obstructive sleep apnea. J Clin Sleep Med 2011; 7: 172-8.

37. Korkmaz M, Korkmaz H, Küçüker F, Ayyıldız SN, Çankaya S. Evaluation of the Association of Sleep Apnea-Related Systemic Inflammation with CRP, ESR, and Neutrophil-to-Lymphocyte Ratio. Med Sci Monit 2015; 21: 477-81. [CrossRef]
Cite this article as: Yiğit E, Önerci Çelebi Ö, Araz Server E, Longur ES. Neutrophil-to-Lymphocyte Ratio and Mean Platelet Volume in Chronic Otitis Media with or Without Cholesteatoma. İstanbul Med J 2018; 19: 162-6. 